\title{
Modeling climatic suitable areas for kedondong (Spondias dulcis) cultivation in central part of Sumatra, Indonesia
}

\author{
IBNA HAYATI ${ }^{1, \boldsymbol{v}}$, ALEX HARTANA ${ }^{2}$, NINA RATNA DJUITA ${ }^{2}$ \\ ${ }^{1}$ Plant Biology Graduate Program, Department of Biology, Faculty of Mathematics and Natural Sciences, Institut Pertanian Bogor. Jl. Raya Dramaga \\ Bogor 16680, West Java, Indonesia. ‘email: nana.ibna@ gmail.com. \\ ${ }^{2}$ Department of Biology, Faculty of Mathematics and Natural Sciences, Institut Pertanian Bogor. Jl. Raya Dramaga Bogor 16680, West Java, Indonesia
}

Manuscript received: 12 October 2019. Revision accepted: 18 November 2019.

\begin{abstract}
Hayati I, Hartana A, Djuita NR. 2019. Modeling climatic suitable areas for kedondong (Spondias dulcis) cultivation in central part of Sumatra, Indonesia. Biodiversitas 20: 3608-3618. Kedondong (Spondias dulcis Parkinson) is a fruit plant native to Society Island (Polynesia, Pacific Islands) and widely cultivated in many tropical regions and countries. However, little is known about the occurrences and potential distribution of kedondong as well as its adaptability to different climate particularly in central part Sumatra. This paper is the first to predict the distribution of kedondong in central part of Sumatra in spatially explicit way. The maximum entropy (MaxEnt) model was used to analyze the geographical distribution of kedondong and to map its climatically suitable habitat in central part of Sumatra. The results showed that the MaxEnt model can be used to predict the climatic suitable areas for kedondong cultivation. Notably, the extent of the potentially suitable habitat was significantly larger than the present occurrence of kedondong in central part of Sumatra. The most suitable areas identified in this study covered the west coast of Sumatra and the central part of Sumatra but did not reach the eastern coast. They included parts of Kuantan Singingi, Indragiri Hulu, Indragiri Hilir and Pelalawan of Riau Provinces, Batang Hari of Jambi Provinces, and western part which include Agam, Tanah Datar, West Pasaman, Limapuluh Kota, Padang Pariaman, Padang and South Pesisir of West Sumatra Provinces. The MaxEnt model performed better than random method with an Area Under Curve (AUC) value of 0.981. Although kedondong is still largely ignored by scientific community and its potential has not been deeply explored, the findings of this study imply that it is very important to develop kedondong germplasm resources which have adaptability to extreme climate in central part of Sumatra.
\end{abstract}

Keywords: Central part of Sumatra, cultivated plant, distribution, kedondong, modeling

\section{INTRODUCTION}

Kedondong (Spondias dulcis Parkinson), a member of Anacardiaceae, is a fruit plant native to Society Island (Polynesia, Pacific Islands) and widely cultivated in many tropical regions and countries (Kostermans 1991; Mitchell and Daly 2015). It is the most common Spondias species in Southeast Asia (Verheij and Coronel 1991). For a long time, kedondong was not commercially cultivated in Indonesia. It was at first considered as a backyard tree or forest plant and found growing mainly as individual trees in rural areas and home gardens. Kedondong attracts little attention to being developed at a commercial scale. However recently, the Central Java Assessment Institute for Agricultural Technology (AIAT) paid attention to kedondong germplasm in Parang Island (Karimunjawa, Central Java) and tried to characterize the cultivars. It has been published by Cempaka et al. (2019). Different from Java region, Indonesian Tropical Fruit Research Institute (ITFRI) in Solok (West Sumatra) confirmed the absence of kedondong germplasm resources in Sumatra mainly from central part of Sumatra (pers. comm).

Central part of Sumatra consists of three provinces, namely Riau, Jambi and West Sumatra. Central part of Sumatra varies in topography and geographical condition, from coastal areas, lowland, highland, mountain and archipelago. The mountainous ranges stretch from north to south along the Sumatra region facing monsoon winds which resulted in varying rainfall patterns (Laumonier 1997). Different rainfall patterns, climate types and temperature also result in the plant grown in Sumatra to be unique in adaptation strategy, resistant to high rainfall and wet climate. These conditions also impacts to the variation in plant species including kedondong.

Kedondong is a unique plant in which all of the plant parts are edible and useful (Verheij and Coronel 1991; Lim 2012). The fruit can be eaten raw, or stewed and used for jams, jellies, and juice. The fruit is also used to make fruit candy, pickles, green salads, and curries. Recently in Bekasi region of West Java, kedondong has been processed to produce various commercial products such as sambal, asinan, pia, pastry, cake, and kedondong juice. However this effort still need to be developed, published and socialized massively. People in Rengat (Indragiri Hulu District, Riau Province, Sumatra) process kedondong into a confection product named as dodol as the typical souvenir from Rengat. Besides the fruit, the young leaves are eaten as salad, added to salted fish, eaten as side dish with rice, used as a substitute for tamarind or lemon to get the sour and savory flavor to dishes, and also added to tenderize meat. The leaves are also eaten by cattle. The young, tender panicles can also be eaten by steaming it or dressing as salad. There are many medicinal uses of fruit, leaves, and bark of kedondong. Several treatments of wounds, sores, 
and burns are being reported of the use of this plant. Kedondong has also a high vitamin $\mathrm{C}$ content compared to its taxonomical relative, mango. The leaves and fruit of kedondong are also used as antioxidant and antimicrobial (Islam et al. 2013). Nowadays, kedondong is also potentially utilized in industry mainly its peel waste can be used as edible coating of fruit (Clarissa et al. 2019).

Little is known about the occurrence of kedondong and its adaptability to different climate and edaphic conditions in Sumatra particularly in central part of Sumatra. Environmental factors, such as temperature, water availability, soil and surface humidity, have significant influences on the distribution of species (Wei et al. 2018). For decades researchers have focused on plant-environment interactions and their impact on the growth of plant. Specifically, studies have revealed that environmental factors not only affect the geographical distribution of plants but also play important role in the formation of active ingredients contained in the plant (Jochum et al. 2007). Climate has significantly worked on the growth and reproduction of plants and therefore become a dominating variable determining the geographical distribution of plant species.

The government of Indragiri Hulu District, Riau Province, has stated that they endorse kedondong cultivation to improve their economic. Unfortunately, nowadays there are not many kedondong trees left, despite the government statement to do rejuvenation for the remaining population. In addition, information related to kedondong in Sumatra has never been limited. Therefore, it is necessary to obtain information about kedondong distribution which can adapt to topography and climate conditions in central part of Sumatra.

Studying the current and potential distribution of species and examining the key environmental factors that affect their growth can help us to understand the overall distribution patterns of species. This information can then be used to determine suitable areas for specific purposes, for example for species conservation and cultivation. Besides, information about the distribution of a plant is useful to know the population, taxonomical variation and habitat suitability, and the potential utilization of such plant.

At present, the common method to study potentially species distribution and environmentally suitable habitat is using species distribution models (SDMs). SDMs predict the niche requirements and potential distribution range of a species using specimen records from museums and a series of environmental variables (Zhang et al. 2018). The most used and popular species distribution models are BIOCLIM (bioclimatic modeling), Domain (domain environmental envelope), CLIMEX (climate change experiment), GARP (genetic algorithm for rule-set production) and MaxEnt (maximum entropy). Each model has its own advantages and disadvantages. Nevertheless, several comparative studies show that MaxEnt has better prediction ability than the other models and it is considered as a robust modeling approach that incorporates statistical models and machine learning for characterizing probability distributions from incomplete information and determining the current and/or projected potential distribution of different species. MaxEnt is selected because of its various advantages: (i) The input species data can be presence-only data; (ii) a spatially explicit habitat suitability map can be directly produced; (iii) the importance of individual environmental variables can be evaluated using a built-in jackknife test; (iv) both continuous and categorical data can be used as input variables (Philips et al. 2006).

The aim of this study was to provide information about the geographical distribution of kedondong (Spondias dulcis) in central part of Sumatra and to identify the climatic suitable areas for its cultivation in central part of Sumatra using MaxEnt and DIVA-GIS. This study mainly focused on the following approach: (i) Dominant climatic variables of kedondong were selected to build a model, (ii) Predicting or identifying the current suitable areas for kedondong cultivation and conservation using such climatic variables. To our knowledge, this is the first study to model suitable location for kedondong cultivation in central part of Sumatra.

\section{MATERIALS AND METHODS}

\section{Study area}

Based on examination of herbarium specimens, either directly or via digital images, in the following institutions: BO and L (acronyms follow Thiers (2019) accessed from sweetgum.nybg.org/ih) there were very few records about Spondias dulcis in Sumatra particularly central part of Sumatra, including West Sumatra, Riau and Jambi provinces, Indonesia. Therefore, recent explorative field surveys (Rugayah et al. 2004) were conducted from July to August 2019 in central part of Sumatra which consists of three provinces, Riau, West Sumatra, and Jambi. The location was selected based on the information from local community about Spondias dulcis (kedondong) occurrences particularly in Kuantan Singingi and Indragiri Hulu districts of Riau, Batang Hari district of Jambi, Agam and Padang Pariaman districts of West Sumatra.

\section{Species occurrence data collection}

Most species distribution models including MaxEnt use geographic coordinates (latitude/longitude) of species occurrences. In this study, the occurrence locations of Spondias dulcis were recorded using a Global Positioning System in a field survey across central part of Sumatra. We recorded and geo-referenced all trees found and isolated individuals of Spondias dulcis using random sampling, totaling 298 records across the central part of Sumatra, resulting in a detailed distribution map (Figure 1). However, only 60 records were used in MaxEnt modeling analysis to minimize sampling bias. All records were imported into Microsoft Excel and saved as ".CSV" format. 


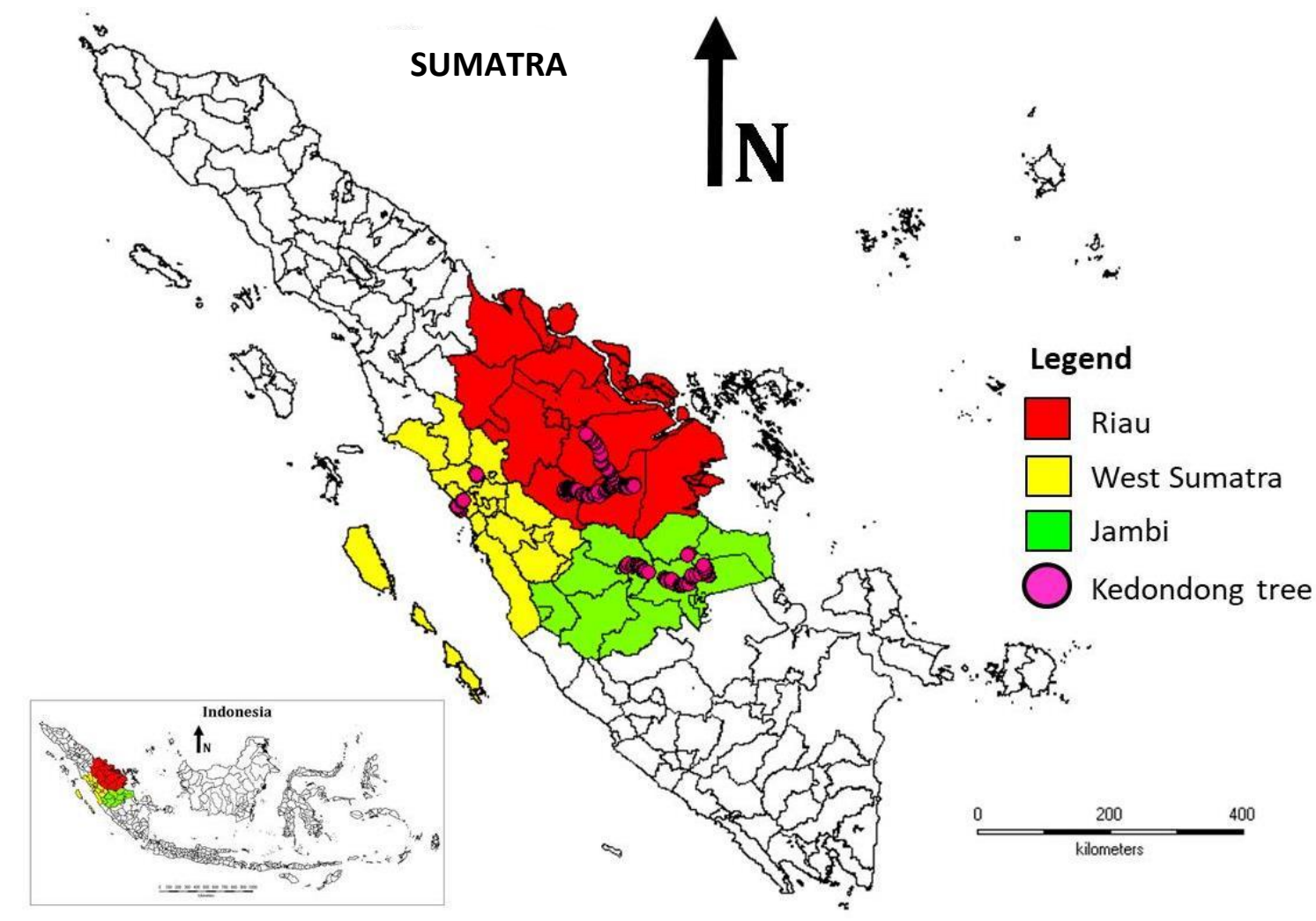

Figure 1. Present distribution of Spondias dulcis (kedondong) in central part of Sumatra, including West Sumatra, Riau and Jambi provinces, Indonesia based on field survey data

\section{Spondias dulcis Parkinson}

Morphological diagnostic

Spondias dulcis Parkinson differs from all other species of Spondias by its remarkable endocarp. There are five main, large spines, curving downwards, originating from the outer edge of the loculi. Numerous smaller spinoses processes, some straight, others curving upwards or downwards, arise from the five lobes of the endocarp. Some of the curved spines join up longitudinally in pairs to form characteristic arches. The (dried) fruit is easily distinguished from its taxonomical relative, Spondias pinnata by the considerable amount of the spongy parenchyma surrounding the endocarp, and by the complete absence of the peripheral, dense, fibrous layer which is so characteristic of Spondias pinnata (Airy Shaw and Forman 1967) (Figure 2).

\section{Description}

Description of Spondias dulcis can be referred to the following references: Spondias cytherea in Airy Shaw and Forman (1967) and Hou (1978); Evia dulcis in Kostermans (1991) and Spondias dulcis in Mitchell and Daly (2015).

\section{Distribution}

Broadly cultivated in tropical regions and countries.

\section{Climatic variables}

In this study, 19 bioclimatic variables were extracted from a global climate database, WorldClim (The new Version 2.0, www.worldclim.org) for the recent period. In the Worldclim database, 'recent period' was defined from 1970 to 2000, and these data have been widely used in creating species distribution models. Bioclimatic variables were calculated from monthly temperature and precipitation values in order to generate more biologically meaningful variables. They were generated through interpolation of average monthly climate data from weather stations at 30 arc seconds $(* 1 \mathrm{~km})$ spatial resolution (Ficks and Hijmans 2017). Environmental variables derived from WorldClim, which have been widely used in the prediction of the potential distribution of species, can reflect the characteristics of temperature and precipitation as well as their seasonal variation characteristics. They are ecologically meaningful variables that explain annual trends, seasonality, and the adaptation of species with extremes of temperature and precipitation.

The 19 bioclimatic variables used were bio1=Annual mean temperature; bio2=Mean diurnal range; bio3=Isothermality; bio4=Temperature seasonality; bio5=Maximum temperature of warmest month; bio6=Minimum temperature of coldest month; bio7=Temperature annual range; bio8=Mean temperature of wettest quarter; bio9=Mean temperature of driest quarter; bio10=Mean temperature of warmest quarter; bio11=Mean temperature of coldest quarter; bio12=Annual precipitation; bio13=Precipitation of wettest month; bio14=Precipitation of driest month; bio15=Precipitation seasonality; bio16=Precipitation of wettest quarter; bio17=Precipitation of driest quarter; bio18=Precipitation of warmest quarter; bio19=Precipitation of coldest quarter. 


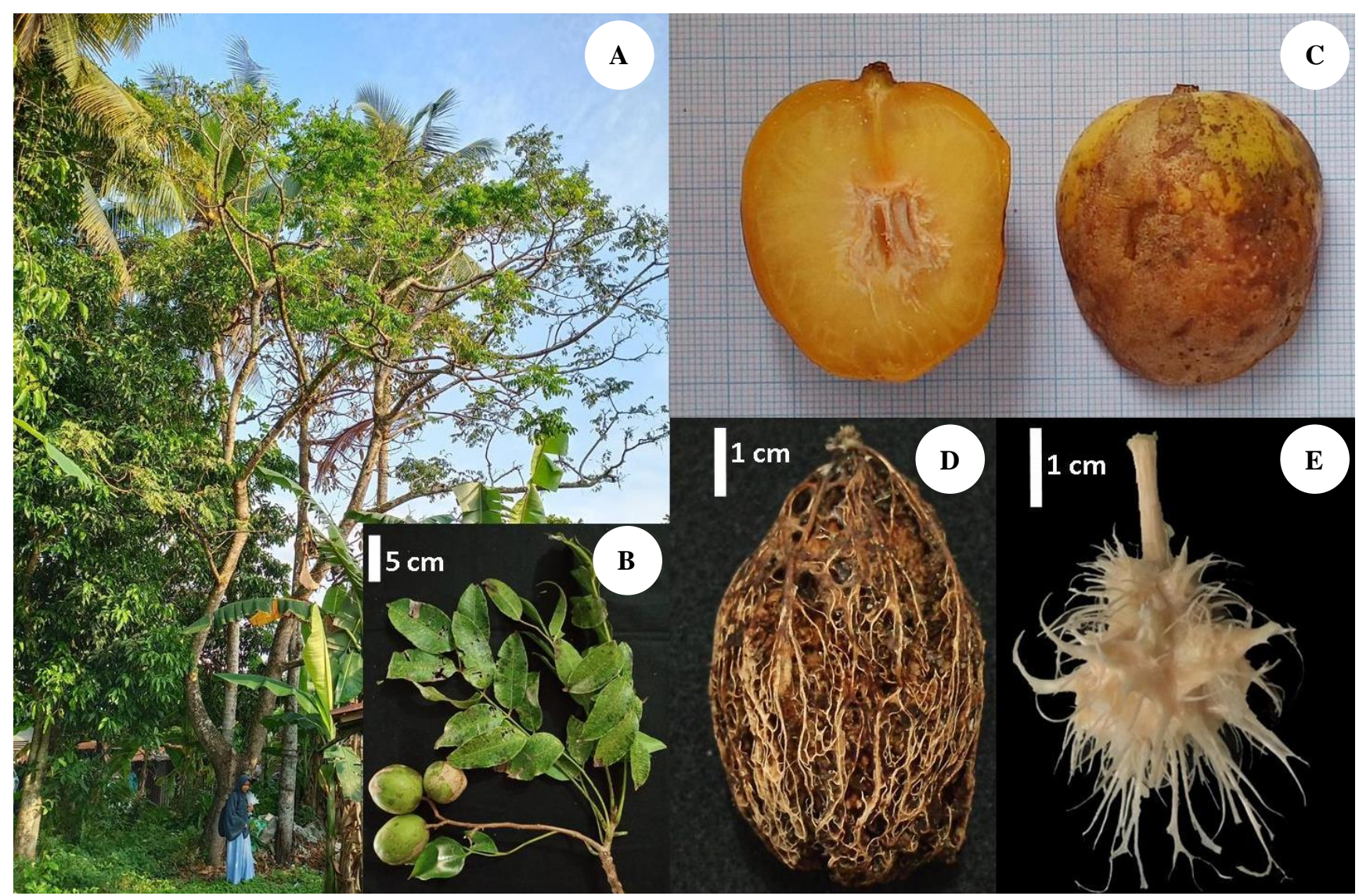

Figure 2. Representative of Spondias dulcis species used in these research. A. Habitus, B. Twig with fruits, C. Longitudinal section of fruit, D. Endocarp enclosed by spongy parenchyma (in overripe fruit), E. Spiny endocarp

Worthington et al. (2016) suggested a method to filter the most influential variables for modeling. Using their method, the jackknife test was employed to evaluate each variable's contribution to the models which resulted in three variables were removed due to their lack of contribution (percent contribution $=0$ ) (Table 1). Then, we eliminated the variables with small contribution rate $(<6 \%)$ and the importance of permutation $(<6 \%$ ) (Table 1) (Wei et al. 2018) in the initial model. In the end, 10 bioclimatic variables (i.e. bio1 $=$ Annual mean temperature, ${ }^{\circ} \mathrm{C}$; bio $2=$ Mean diurnal range, ${ }^{\circ} \mathrm{C}$; bio3= Isothermality; bio4= Temperature seasonality; bio8 $=$ Mean temperature of wettest quarter, ${ }^{\circ} \mathrm{C}$; bio9 $=$ Mean temperature of driest quarter, ${ }^{\circ} \mathrm{C}$; bio12= Annual precipitation, $\mathrm{mm}$; bio15= Precipitation seasonality; bio16= Precipitation of wettest quarter, $\mathrm{mm}$; bio17 = Precipitation of driest quarter, $\mathrm{mm}$ ) were used to model the current distributions of Spondias dulcis in central part of Sumatra. The percent contribution and permutation importance are important factors that measure the importance of the environmental variables. The permutation importance is up to the final performance of the model rather than the path used in an individual run and therefore is better for evaluating the importance of a particular variable (Songer et al. 2012). Those data are statistically downscaled from a Global Circulation Model (GCM) based on the sum of interpolated anomalies to highresolution monthly climate surfaces from the WorldClim (Shrestha and Bawa 2014).

\section{Species distribution modeling}

MaxEnt algorithm version 3.4.1 (Phillips et al. 2017) was used for mapping the potential geographic distribution of Spondias dulcis in central part of Sumatra. The software was obtained from https://biodiversityinformatics.amnh.org /open_source/maxent/ and can be downloaded freely for scientific research. We used the maximum entropy model because it has been shown to perform better with small sample sizes relative to other modeling methods. Maxent (Phillips et al. 2017) uses presence-only data to predict the distribution of a species based on the theory of maximum entropy. This software attempts to estimate a probability distribution of species occurrence that is closest to uniform while still subject to environmental constraints. 
Table 1. Analysis of variable contribution and permutation importance

\begin{tabular}{llcc}
\hline \multicolumn{1}{c}{ Code } & \multicolumn{1}{c}{ Environmental variables } & Percent contribution (\%) & Permutation importance (\%) \\
\hline bio15 & Precipitation Seasonality & 15.8 & 5.6 \\
bio4 & Temperature Seasonality & 14.5 & 32.2 \\
bio9 & Mean Temperature of Driest Quarter & 13.4 & 2 \\
bio8 & Mean Temperature of Wettest Quarter & 10.2 & 14.5 \\
bio2 & Mean Diurnal Range & 10.1 & 3.7 \\
bio17 & Precipitation of Driest Quarter & 9.3 & 0.2 \\
bio16 & Precipitation of Wettest Quarter & 8.7 & 9.9 \\
bio3 & Isothermality & 7.5 & 0.5 \\
bio18 & Precipitation of Warmest Quarter & 2.4 & 1.9 \\
bio5 & Max Temperature of Warmest Month & 2.2 & 3.8 \\
bio6 & Min Temperature of Coldest Month & 1.5 & 3.8 \\
bio19 & Precipitation of Coldest Quarter & 1.2 & 1 \\
bio12 & Annual Precipitation & 1 & 8.9 \\
bio13 & Precipitation of Wettest Month & 0.9 & 2.2 \\
bio7 & Temperature Annual Range & 0.7 & 3.2 \\
bio1 & Annual Mean Temperature & 0.6 & 6.6 \\
bio11 & Mean Temperature of Coldest Quarter & 0 & 0 \\
bio14 & Precipitation of Driest Month & 0 & 0 \\
bio10 & Mean Temperature of Warmest Quarter & 0 & 0 \\
\hline
\end{tabular}

In our models, default settings were used in MaxEnt so that the complexity of the model varied depending upon the number of data points used for model fitting. Jackknife analyses were performed to determine variables that reduce the model reliability when omitted. The habitat suitability curves of each variable were calculated, and the contributions of each variable to the habitat model of Spondias dulcis were calculated using the software's builtin jackknife test. The jackknife test (systematically leaving out each variable) was used to measure which were the dominant climatic factors determining potential distribution of the species. We used the Area Under the Curve (AUC) of Receiving Operator Curve (ROC) to evaluate model performance. The value of AUC ranges from 0 to 1 . An AUC value of 0.50 indicates that model did not perform better than random, whereas a value of 1.0 indicates perfect discrimination. The model with the highest AUC value was considered as the best model.

For display and further analysis, we imported the results of the MaxEnt models predicting the presence of Spondias dulcis (0-1 range) into DIVA-GIS software version 7.5 (Hijmans et al. 2012). The habitat suitability in the map was divided into four levels: unsuitable area (0.0-0.3); the lowly suitable area $(0.3-0.5)$; the moderately suitable area $(0.5-0.7)$ and the highly suitable are (0.7-1.0) (Zhang et al. 2018).

\section{RESULTS AND DISCUSSION}

\section{Result validation}

Testing or validation is required to assess the predictive performance of the model. We evaluated models using threshold-independent ROC analysis. The AUC of high values refers to good results that significantly differ from random predictions. The Maxent model output provided satisfactory results with the given set of training and test data and the final model had high accuracy with an AUC value of 0.981 (Figure 3 ). It is important to note that the prediction result was consistent with the extent of areas of original occurrence records. The output results of ASCII format were imported to DIVA-GIS 7.5 and were used to conduct suitability classification and visual interpretation.

\section{Model performance and contribution of climatic variables}

The results of this study showed that the accuracy of prediction of suitable habitat for kedondong was found to be excellent (AUC $=0.981$, Figure 3 ), suggesting that the selected climatic variables predicted the current distribution of kedondong very well. The key climatic factors could be determined according to their contributions to the modeling process. The key climatic factors included bio15 (precipitation seasonality, 16.2\%), bio4 (temperature seasonality, $16.3 \%$ ), bio9 (mean temperature of driest quarter, $14.4 \%$ ), bio8 (mean temperature of wettest quarter, $10.3 \%$ ) which accounted for almost $57.2 \%$ of the model prediction (Figure 4.A). Considering the importance of permutation, temperature seasonality (bio4, 29.1\%), precipitation seasonality (bio15, 18\%), mean temperature of wettest quarter (bio8, 13\%) and annual mean temperature (bio1, 9.7\%) were much higher than others (Figure 4.B). The jackknife test showed that temperature seasonality (bio4), mean temperature of wettest quarter (bio8), mean temperature of driest quarter (bio9) and precipitation seasonality (bio15) were the main variables (Figure 5). However, isothermality (bio3) and precipitation of driest quarter (bio17) also revealed significantly higher gain as compared with the other environmental variables. In other words, precipitation and temperature were played a vital role in predicting the probable distribution of kedondong. 


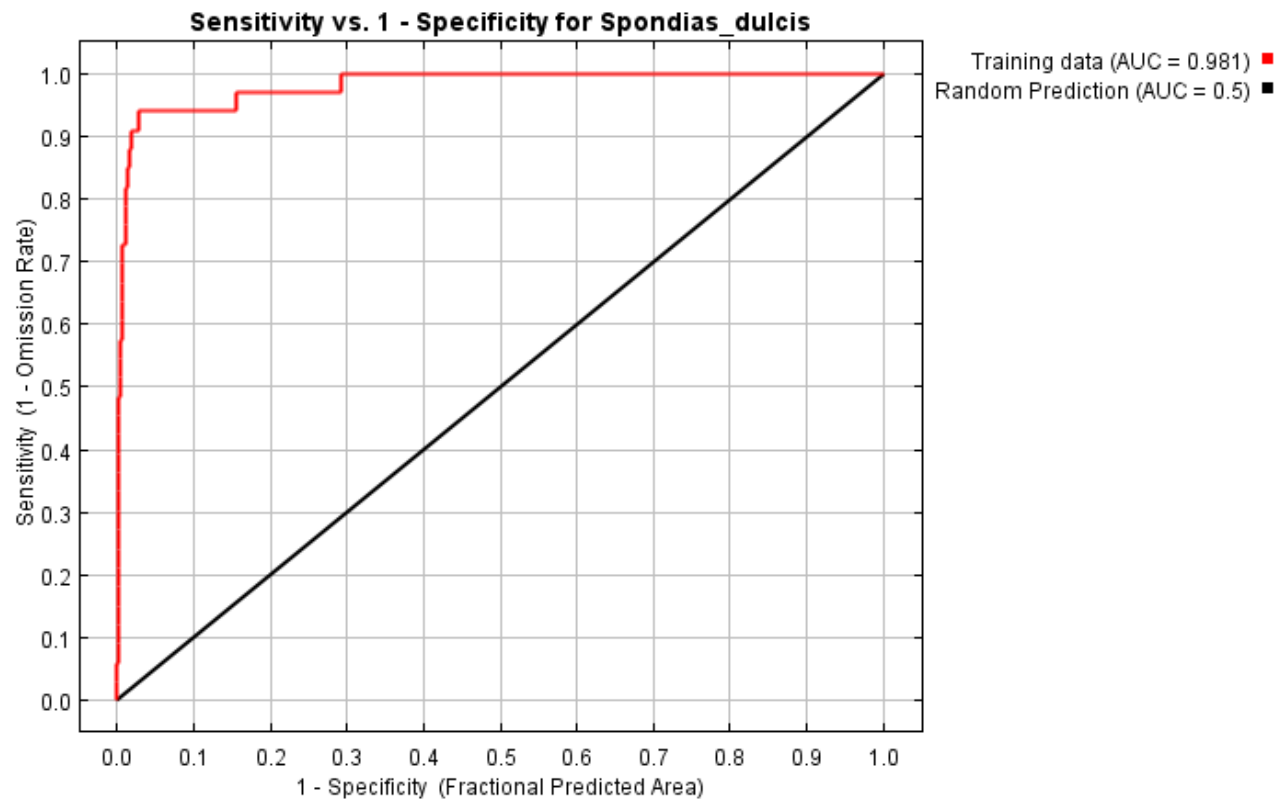

Figure 3. The results of the AUC curves in developing kedondong's habitat suitability model

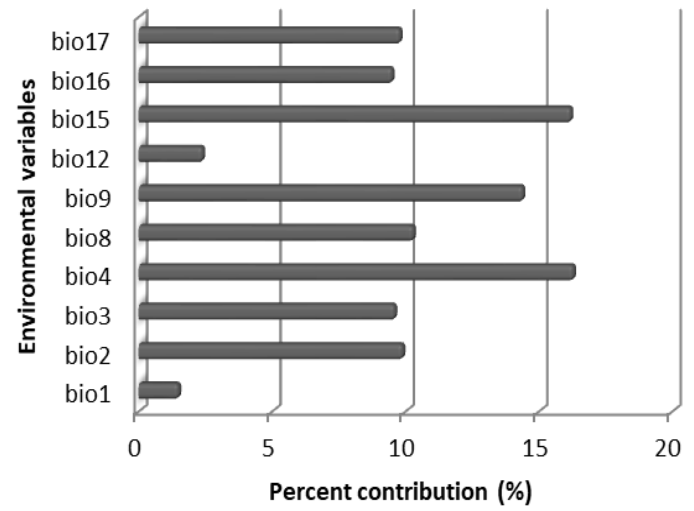

A

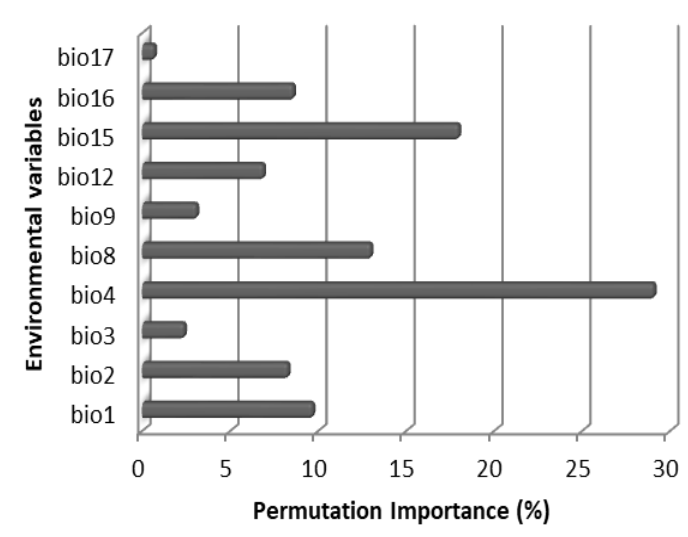

B

Figure 4. (A) The contribution of each climatic variable in predicting suitable habitat for kedondong cultivation. (B) Variables permutation importance in predicting suitable habitat for kedondong cultivation. bio1=Annual mean temperature; bio2=Mean diurnal range; bio3=Isothermality; bio4=Temperature seasonality; bio8=Mean temperature of wettest quarter; bio9=Mean temperature of driest quarter; bio12=Annual precipitation; bio15=Precipitation seasonality; bio16=Precipitation of wettest quarter; bio17=Precipitation of driest quarter.

\section{Variables' response to suitability}

The relationship between the probability of Spondias dulcis distribution with environmental variables can be seen in the response curve generated by the Maximum Entropy model. The curves show how the predicted probability of Spondias dulcis presence changes as each environmental variable is varied, keeping all other environmental variables at their average sample value. Response curves show the quantitative relationship between environmental variables and the logistic probability of presence (also known as habitat suitability), and they deepen the understanding of the ecological niche of the species (Yi et al. 2016). The response of Spondias dulcis to four climatic variables are illustrated in Figure 6.
The response curve showed the suitability of Spondias dulcis occurs in areas with temperature seasonality range between 20-60, indicating the small variability of temperature. Temperature seasonality defined as the amount of temperature variation over a given year (or averaged years) based on the standard deviation (variation) of monthly temperature averages (O'Donnell and Ignizio 2012). These results is a representative temperature seasonality range to explain the optimal temperature seasonality required by Spondias dulcis. Based on the response curve, the suitable annual mean temperature, mean temperature of wettest quarter and mean temperature of driest quarter are higher than $25^{\circ} \mathrm{C}$, indicating Spondias dulcis prefers warm habitat. 


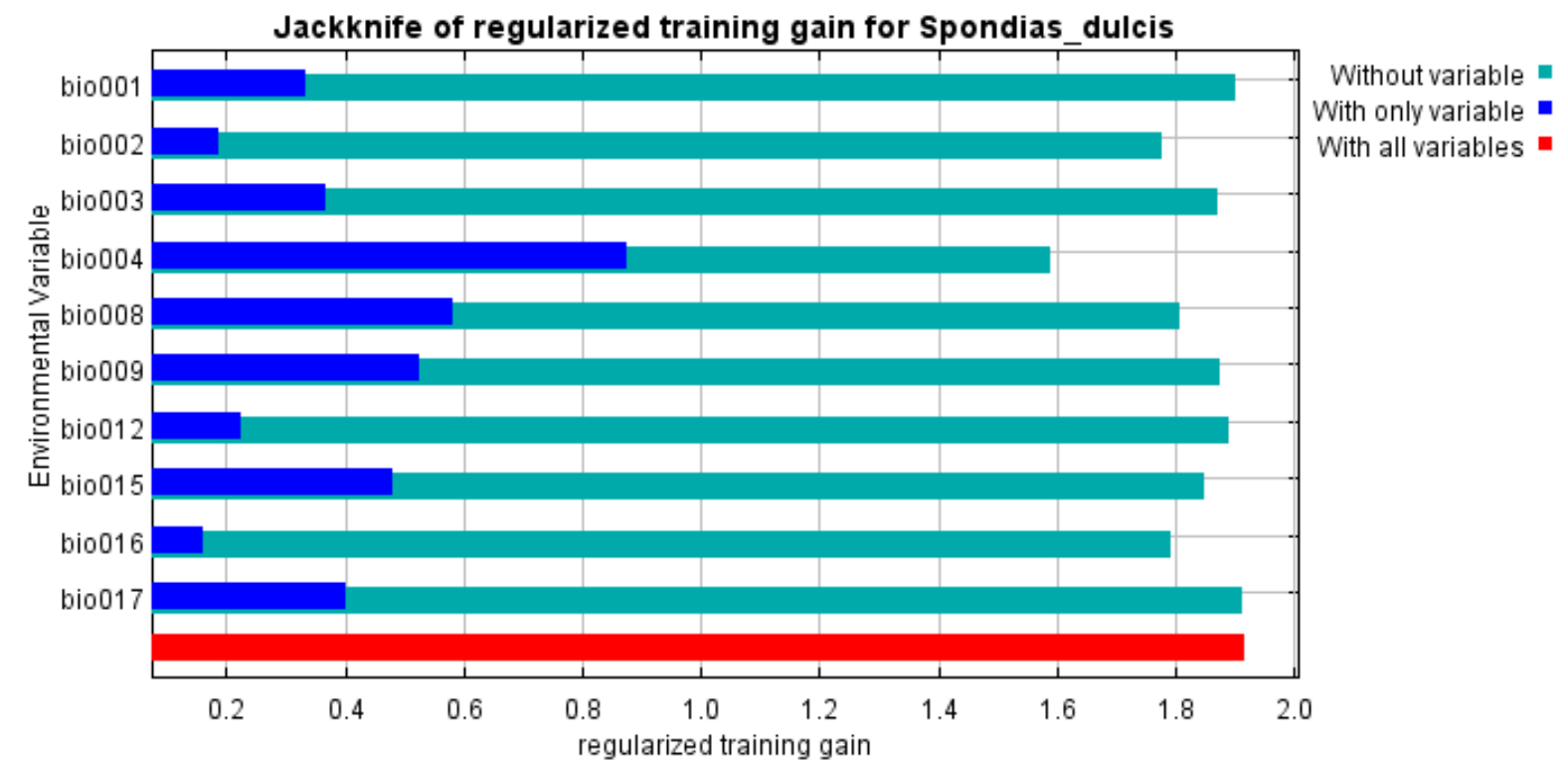

Figure 5. Jackknife test of variable importance in predicting suitable habitat for kedondong cultivation. bio1=Annual mean temperature; bio2=Mean diurnal range; bio3=Isothermality; bio4=Temperature seasonality; bio8=Mean temperature of wettest quarter; bio9=Mean temperature of driest quarter; bio12=Annual precipitation; bio15=Precipitation seasonality; bio16=Precipitation of wettest quarter; bio17=Precipitation of driest quarter.
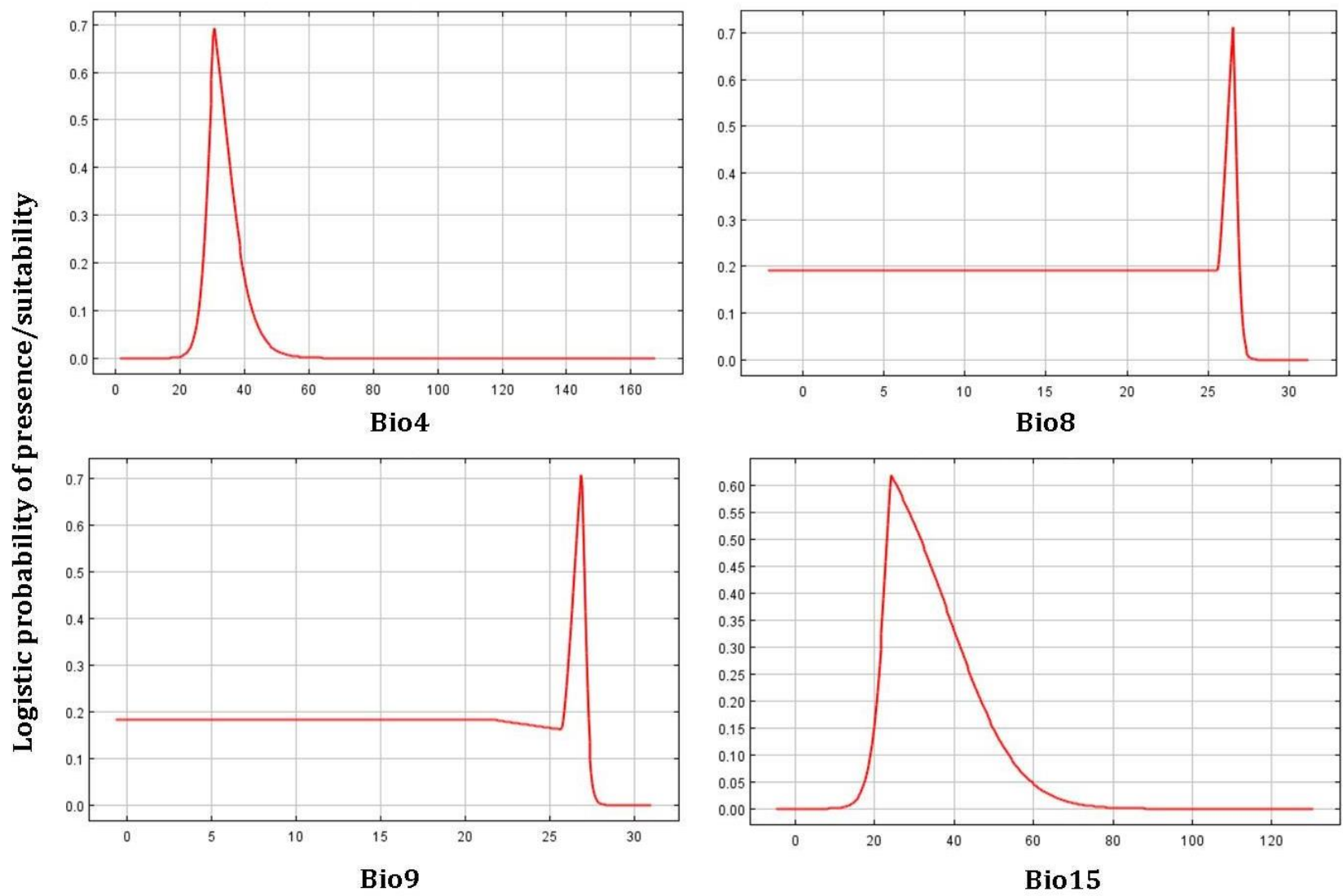

Figure 6. Response curve of Spondias dulcis Parkinson to four key climatic variables. (Bio4= Temperature seasonality; Bio8= Mean temperature of wettest quarter, ${ }^{\circ} \mathrm{C}$; Bio $9=$ Mean temperature of driest quarter, ${ }^{\circ} \mathrm{C}$; Bio15= Precipitation seasonality) 
The response curve showed the suitability of Spondias dulcis occurs in areas with precipitation seasonality range between 14-80 \%, indicating the great variability of temperature. Precipitation seasonality is a measure of the variation in monthly precipitation totals over the course of the year. This index is the ratio of the standard deviation of the monthly total precipitation to the mean monthly total precipitation (also known as the coefficient of variation) and is expressed as a percentage (O'Donnell and Ignizio 2012). These results are a representative precipitation seasonality range to explain the optimal precipitation seasonality required by Spondias dulcis. Based on the response curve, the suitable annual mean precipitation range between 2000-3200 mm/year, indicating Spondias dulcis prefers both dry and wet climate.

\section{Predicted current potential distribution of Spondias dulcis}

Using DIVA-GIS 7.5, a climatically suitable habitat map for Spondias dulcis was created based on observed occurrences and current environmental conditions projected by the MaxEnt model are shown in Figure 7. The highly suitable areas were mainly located in eleven districts (kabupaten): IHU (Indragiri Hulu), KS (Kuantan Singingi), PL (Pelalawan), IHI (Indragiri Hilir), WP (West Pasaman), AG (Agam), TD (Tanah Datar), LK (Limapuluh Kota), PR (Padang Pariaman), PD (Padang) and BH (Batang Hari). The moderately suitable areas extended to RHI (Rokan Hilir), PSL (South Pesisir), TB (Tebo), WTJ (West Tanjung Jabung) and MJ (Muaro Jambi). The lowly suitable areas and in addition to the above districts, there were also some small extent of suitable areas in KM (Kampar), PKU (Pekanbaru), SK (Siak), BK (Bengkalis), RHU (Rokan Hulu), DH (Dharmasraya), PS (Pasaman), SS (South Solok), SO (Solok) and SJ (Sijunjung). Other districts were mainly located in the very southern part of Jambi, including BG (Bungo), KR (Kerinci), MR (Merangin), SL (Sarolangun); ETJ (East Tanjung Jabung), northern part of South Pesisir, eastern part of Pelalawan and Indragiri Hilir and Meranti archipelago were potentially unsuitable areas. Notably, the extent of the potential suitable habitat for cultivation was significantly larger than the present occurrence of kedondong in central part of Sumatra.

\section{CENTRAL SUMATRA}

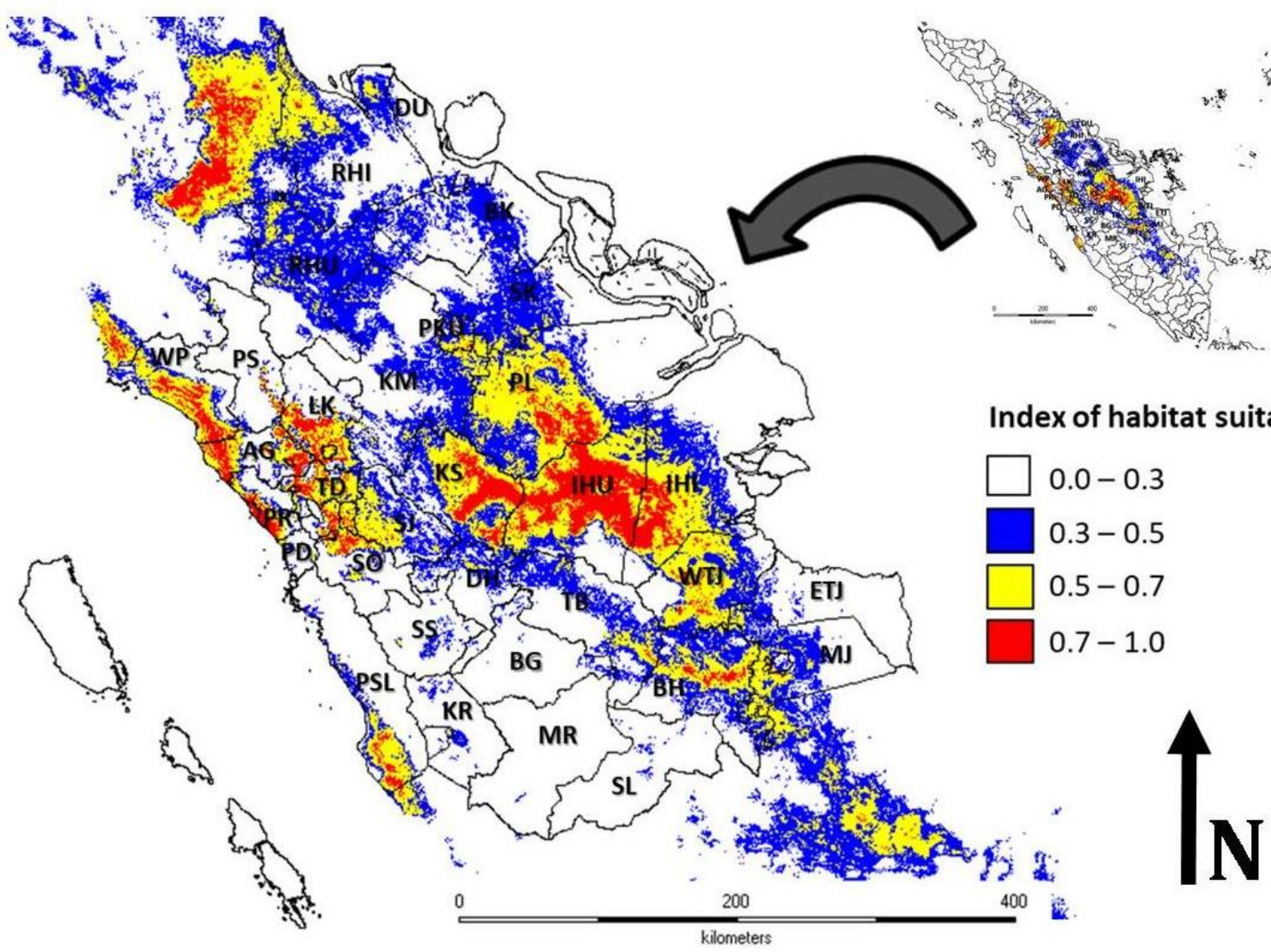

Figure 7. Current suitable climatic distribution of Spondias dulcis in central part of Sumatra. KS (Kuantan Singingi), IHU (Indragiri Hulu), IHI (Indragiri Hilir), PL (Pelalawan), RHU (Rokan Hulu), RHI (Rokan Hilir), PKU (Pekanbaru), KM (Kampar), SK (Siak), BK (Bengkalis), DU (Dumai), WTJ (West Tanjung Jabung), ETJ (East Tanjung Jabung), BH (Batang Hari), MJ (Muaro Jambi), TB (Tebo), BG (Bungo), MR (Merangin), SL (Sarolangun), KR (Kerincin, WP (West Pasaman), PS (Pasaman), LK (Limapuluh Kota), TD (Tanah Datar), AG (Agam), PR (Padang Pariaman), PD (Padang), PSL (South Pesisir), SJ (Sijunjung), SO (Solok), SS (South Solok), DH (Dharmasraya) 


\section{Discussion}

This study is the first to explore the geographical distribution and predict the climatically suitable habitat of kedondong (Spondias dulcis) in central part of Sumatra using MaxEnt. MaxEnt has been the most widely used modeling tool because it can easily and rapidly provide detailed results on the current and past occurrences of a target species (Fourcade et al. 2014). In this study, the MaxEnt model demonstrated an excellent and accurate level of prediction with higher AUC values (Elith et al. 2006). We found that the AUC value of the MaxEnt model when predicting climatic suitable areas for Spondias dulcis was above 0.980 .

Our simulation of the potential distribution of Spondias dulcis was only based on occurrence data in exotic areas which indicates that the climatic niche of the species we have simulated is fundamental niche (Booth 2017). Some previous studies (e.g. Soberon and Arroyo-Pena 2017) suggested that fundamental niche is always broader than the realized niche. In this study, the potential suitable habitat of Spondias dulcis was predicted only based on bioclimatic variables (including four main variables: (temperature seasonality, precipitation seasonality, mean temperature of driest quarter and mean temperature of wettest quarter), while other abiotic factors, such as soil, hydro-geological and altitude were excluded. Yet, climatic factors might remain the most crucial factors that affect plant regeneration, growth and the spread of its populations (Zhang et al. 2018). Nonetheless, other key environmental factors that affect habitat suitability need to be considered for cultivation planning and resource utilization of plants in the potential regions in the future. Biophysical factors such as topography, climate and edaphic/soil were mainly important to determine land suitability for planting particular crops in order to be attained higher growth rates and yields. However, without high social feasibility value, a greater risk that cultivation on these potential areas may be unsuccessful in the long term (Budiharta et al. 2016).

Little is known about the existence and distribution of kedondong (Spondias dulcis) in central part of Sumatra. Miquel (1860) assumed that all of Spondias species in Sumatra were never known and well documented. The last publication by Hartini and Puspitaningtyas (2009) stated Spondias dulcis were found in the forest of West Sumatra. In this study, exploration conducted in July to August 2019 found many occurrences of Spondias dulcis in central part of Sumatra. The main locations were in Indragiri Hulu of Riau Province, Batang Hari of Jambi and Padang Pariaman of West Sumatra. Based on the observation in the field, almost all Spondias dulcis plants were found near water bodies. Exploration in Riau Province particularly in Kuantan Singingi and Indragiri Hulu, kedondong trees were found along the Indragiri River. Similarly, the exploration in Jambi Province, mainly in Tebo and Batang Hari, also found Spondias dulcis trees in the river banks. For the exploration in West Sumatra notably in Padang Pariaman, the trees were found near the coastal area and grassland while in Agam the trees were found in paddy field, house yard and wayside. Other than aforementioned areas, old kedondong trees were also found in palm oil plantation and community gardens. Based on information from local residents, the old kedondong tree in Agam was ever visited by researchers from the United States. This implies a challenge for us that we should pay greater attention to conservation and utilization of germplasm resources of our cultivated plants.

Based on distribution of the main soils, central part of Sumatra divided into five soil regions (FAO 1979): cambisol-andosol association in western region including a large part of West Sumatra; acrisols in central region including small part of West Sumatra and a large part of Riau and Jambi; histosol in eastern region including eastern coast of Riau and Jambi. While in western island is podzols and in eastern island is luvisols. Kedondong is mainly distributed in cambisol-andosol association and acrisols region in which these two soil regions have mediumtextured and well-drained humic which preferred by kedondong tree.

In the studied areas, most of the old kedondong trees have been cut down while those still remaining were generally tall and rarely pruned, so the branches were far above the ground. Within the same location and relatively close in distance, kedondong trees were found to have different flowering times. Sometimes, the kedondong trees found were ready to fall out the leaves, the other trees were ready to flowering and the others still had leaves, flowers, and fruits together. The diversity of kedondong characteristics as mentioned above raises the hypothesis that the trees have different responses to different environments despite being in the same location. The kedondong trees in the same location were not known whether it was originally from the same origin or not. Information from residents stated that some of the kedondong they planted came from grafts or seeds, but some explained that the kedondong trees were have been there since they were young but not previously known from which area it originated.

The most suitable area identified in this study covered the west coast of Sumatra and the central part of Sumatra but did not reach the eastern coast. They included parts of Kuantan Singingi, Indragiri Hulu, Indragiri Hilir and Pelalawan of Riau Province, Batang Hari of Jambi Province, and western part which include Agam, Tanah Datar, West Pasaman, Limapuluh Kota, Padang Pariaman, Padang and South Pesisir of West Sumatra. Based on potential suitable habitat resulted from MaxEnt, several regions were also moderately suitable for kedondong cultivation including to RHI (Rokan Hilir), PSL (South Pesisir), TB (Tebo), WTJ (West Tanjung Jabung) and MJ (Muaro Jambi).

Based on climate type and precipitation, Sumatra is divided into two regions, from wet to dry climate. Western part of Sumatra has an average rainfall of up to 3000-4000 $\mathrm{mm}$ /year, while central to eastern part of Sumatra has an average rainfall of 2000-3000 mm/year. Most of the regions in central part of Sumatra have a wet climate type with rainfall ranging from 2000-3000 mm/year, 3000-4000 $\mathrm{mm} /$ year to $4000-5000 \mathrm{~mm}$ year. Dry climate type with rainfall of 1000-2000 mm/year only found in certain areas, namely the border area of Riau and North Sumatra in the 
eastern, the border area of Jambi and West Sumatra and the border area of Jambi and South Sumatra (IAHRI 2003).

The MaxEnt model has predicted that different species have different potentially suitable habitat. Precipitation is likely related to leaves emergence and flowering time of kedondong. During the dry season, kedondong leaves fall out completely and in the rainy season, it will spring quickly. Based on agroclimate map of IAHRI 2003, kedondong was found in region with varying types of climate, ranging from areas with climate type IIIC (2000$3000 \mathrm{~mm} /$ year), type IVC (3000-4000 mm/year) to type VC (4000-5000 mm/year). Although kedondong prefers dry climate type, the cultivation of kedondong can also be implemented in areas with wet climate types in central part of Sumatra. This resulted kedondong in central part of Sumatra experiencing adaptation to the wet climate and high rainfall.

More importantly, our research confirmed that kedondong plants were mainly distributed from 0 to $877 \mathrm{~m}$ above sea level, crossing central part of Sumatra. Based on MaxEnt, environmental variables such as precipitation and temperature play important role in kedondong habitat. Notably, the size of the potential suitable habitat is significantly larger than the present occurrence of kedondong in central part of Sumatra. Kedondong can only grow in certain areas so that it has the narrowest distribution range in Sumatra. The climatically suitable habitats of kedondong were mainly distributed in the wet climate types area, covering the west coast of Sumatra and the central part of Sumatra but did not reach the eastern coast. These findings have not been reported before for this species. Although kedondong is still largely ignored by scientific community and its potential has not been deeply explored but it is very important to develop kedondong germplasm resources that have adaptability to extreme climate in central part Sumatra that differ from its native area.

\section{ACKNOWLEDGEMENTS}

We would like to express high appreciation and gratitude to the Indonesia Endowment Fund for Education (LPDP) for their support in this research.

\section{REFERENCES}

Booth TH. 2017. Assessing species climatic requirements beyond the realized niche: some lessons mainly from tree species distribution modelling. Clim Ch 145: 259-271.

Budiharta S, Meijaard E, Wells JA, Abram NK, Wilson KA. 2016. Enhancing feasibility: Incorporating a socio-ecological systems framework into restoration planning. Environ Sci Pol 64: 83-92.

Cempaka IG, Susila A, Haskarini D, Malik A. 2019. Morphological Characterization of Kedondong Parang Karimunjawa. National Seminar in the framework of the 43rd UNS Anniversary in 2019. Solo [Indonesian]

Clarissa, Claudia G, Putri MT, Handoyo CC, Firdayanti SA, Milka, Kiyat WE. 2019. Review: Extraction of Pectin from Kedondong peel waste
(Spondias dulcis) and its utilization for edible coating in fruit. Int $\mathbf{J}$ Chem Anal 2 (1): 1-10. [Indonesian]

Elith J, Graham CH, Anderson RP, Dudi'k M, Ferrier S, Guisan A. 2006. Novel methods improve prediction of species' distribution from occurrence data. Ecography 29: 129-151.

FAO. 1979. FAO-Unesco Soil map of the world 1:5.000.000. Volume IX. Southeast Asia. Unesco, Paris.

Fick SE, Hijmans rj, 2017. Worldclim 2: New 1-km spatial resolution climate surfaces for global land areas. Int J Climatol 37 (12): 43024315.

Fourcade Y, Engler JO, Rodder D, Secondi J. 2014. Mapping species distribution with MAXENT using a geographically biased sample of presence data: a performance assessment of methods for correcting sampling bias. PloS One 9 (5): e97122. DOI: 10.1371/journal.pone.0097122.

Hartini S, Puspitaningtyas DM. 2009. Plant diversity of Sumatra Island. LIPI Press, Jakarta. [Indonesian]

Hijmans RJ, Guarino L, Mathur P. 2012. DIVA-GIS version 7.5 Manual. https://www.diva-gis.org/

Hou D. 1978. Anacardiaceae. In van Steenis, Flora Malesiana, Series 1, 8 (3): 479-486.

IAHRI. 2003. Map of Indonesian Agricultural Climate Resources (scale 1: 1,000,000). Center for Land and Agro-climate Research and Development. Bogor. [Indonesian]

Islam SMA, Ahmed KT, Manik MK, Wahid MA, Kamal CSI. 2013. A comparative study of the antioxidant, antimicrobial, cytotoxic and thrombolytic potential of the fruits and leaves of Spondias dulcis. Asian Pac J Trop Biomed 3 (9): 682-691.

Jochum G, Mudge K, Thomas R. 2007. Elevated temperatures increase leaf senescence and root secondary metabolite concentrations in the understory herb Panax quinquefolius (Araliaceae). Am J Bot 94 (5):819-826.

Kostermans AJGH. 1991. Kedondong, Ambarella, Amra, the Spondiadeae (Anacardiaceae) in Asia and the Pacific area. Karya B 78 Printing Works, Bogor, Indonesia.

Laumonier Y. 1997. The Vegetation and physiography of Sumatra. Geobotany 22, Klüwer Academic, Netherlands.

Lim TK. 2012. Edibel Medicinal and Non-Medicinal Plants Volume 1. Fruits. Springer, Dordrecht.

Miquel FAW. 1860. Flora van Nederlandsch Indie. Erste bijvoegsel. Sumatra, zijne plantenwereld en hare voortbrengselen. CG van der Post, Amsterdam.

Mitchell JD, Daly DC. 2015. A revision of Spondias L. (Anacardiaceae) in the Neotropics. Phytokeys 55:1-92.

O’Donnell MS, Ignizio DA. 2012. Bioclimatic predictors for supporting ecological applications in the conterminous Geological Survey Data Series 691, USA.

Philips SJ, Anderson RP, Schapire RE. 2006. Maximum entropy modeling of species geographic distributions. Ecol Model 190: 231-259.

Phillips SJ, Robert PA, Dudik M, Schapire RE, Blair M. 2017. Opening the black box: an open-source release of Maxent. Ecography 887-893.

Shrestha UB, Bawa KS. 2014. Impact of climate change on potential distribution of Chinese caterpillar fungus (Ophiocordyceps sinensis) in Nepal Himalaya. PLoS One 9 (9). DOI: 10.1371/journal.pone.0106405.

Soberon J, Arroyo-Pena B. 2017. Are fundamental niches larger than the realized? Testing a 50-year-old prediction by Hutchinson. PloS One 12 (4): e0175138. DOI: 10.1371/journal.pone.0175138.

Songer M, Delion M, Biggs A, Huang Q. 2012. Modeling impacts of climate change on giant panda habitat. Int J Ecol 2012: 108752, DOI: 10.1155/2012/108752

Verheij EWM, Coronel RE. (eds). 1991. Plant Resources of South-East Asia No. 2. Edible Fruits and Nuts. Pudoc, Wageningen.

Wei B, Wang R, Hou K, Wang X, Wu W. 2018. Predicting the current and future cultivation regions of Carthamus tinctorius L. using Maxent model under climate change in China. Global Ecology and Conservation 16: e00477. DOI: 10.1016/j.gecco.2018.e00477.

Worthington TA, Zhang T, Logue DR, Mittelstet AR, Brewer SK. 2016. Landscape and flow metrics affecting the distribution of a federallythreatened fish: improving management, model fit, and model transferability. Ecol Model 342: 1-18.

Zhang X, Li G, Du S. 2018. Simulating the potential distribution of Elaeagnus angustifolia $\mathrm{L}$ based on climatic constraints in China. Ecol Eng 113: 27-34. 